\title{
Adolescents ${ }^{\text {ee }}$ Aggression in Relation to Peer Pressure and Family Relationship
}

\author{
Rajesh Kumar ${ }^{1}$, Beenu Varma ${ }^{2}$ \\ ${ }^{1}$ Assistant Professor, Dept of Psychology, Post Graduate Government College, Sec-46, Chandigarh \\ ${ }^{2}$ Research Scholar, Department of Psychology, Panjab University, Chandigarh
}

\begin{abstract}
Adolescent is the stage between childhood and adulthood. It is the time when adolescent move from dependency on their parents to independency and maturity. This stage brings so many changes. Family relationship plays an important role in this stage. Aggression also develops which sometimes generates from peer pressure. The aim of the present investigation is to study the adolescent aggression in relation to peer pressure and family environment. Sample of the study consisted of 210 adolescents (107 Male and 103 Female), ranging in the age of 13-19 years and were randomly selected from different schools of Chandigarh. The sample responded to Manifestation of Aggression (R. A. Singh, 1986) which consists of 50 items, Peer Pressure (Singh \& Saini, 2010) which consists of 25 items and Family Relationship inventory by Sherry \& Sinha, (1987) which consists of 150 items. To find out the results descriptive statistics, $t$ - test and correlation matrix were calculated and it was found that there is non significant difference between boys and girls on aggression, family affection and family care and the values comes out to be $0.378,0.613$ and 0.47 respectively. It was also revealed that there is significant difference between boys and girls on peer pressure and family behaviour and $p$ value found to be 0.003 and 0.020 respectively. It was also revealed that there is significant association between aggression and family care and between peer pressure and family behaviour.
\end{abstract}

Keywords: Adolescent, Family relationship, Peer pressure, Care.

\section{Introduction}

Adolescents is the stage of identity formation where one continue the journey of self discovering, they continually have to adjust to new experiences which is both stressful and anxiety provoking. Changes includes the efforts to understand one"s self, changes occur in the social contexts of adolescents lives and their relation with parents and peers. In the late adolescents period there occurs so many psychological changes in which there is pressure from parents as well as from peers. It is a period of active growth and development. Some adolescents can cope up easily with all these changes but some fail adopt these changes and leads towards the aggression, violence, maladjustment etc. Aggressive behaviour is one of the most frequently reported problems of adolescents. Aggression is generally defined as a behavioral act that results in harming and hurting others. There are different types of aggression depending on the intentions of the person who is aggressive and the situations that stimulates the aggressive response. Aggression may be proactive or reactive; overt or covert; or physical, verbal or relational (Werner \& Crick, 2004). Aggression is a behaviour that can be directed toward others or internally and which can be either constructive or destructive. Adolescents uses verbal aggression also which includes bullying, threats or yelling.

The children who were irritable, had strong negative emotional reactions, who lacked persistence were over reactive and difficult to soothe turned out to be more aggressive at the later stage. Family environment is the most important factor for psychosocial adjustment. If adolescents found supportive and healthy family they may no longer hope for strong peer group. If they are being accepted by their family members they feel confident. It is observed that the peer pressure plays an important role in the manifestation of aggression. Peer pressure is the "influences and pressures adolescents feel from their peers" (Adriaansz, 2002). Adolescents inevitably watch towards their peers for their approval, support and acceptance. Peer pressure ranges from positive effects to negative effects. Pung et al (2015) found that there were significant positive relationship between peer pressure and aggression among adolescents. Researchers found that peer pressure is the effective predictor in explaining adolescents" aggression level (Yavuzer et al, 2014).

The problems like road rage, drinking, smoking, drug addiction, violence and fights due to excessive aggression are also the outcome of peer pressure. It becomes the psychological need of an adolescent to be accepted and appreciated as a part of that group and that need is accompanied by peer pressure. Many a times the adolescents are so affected by peers that they start behaving like them unknowingly. Peers may influence each other to engage in antisocial behaviour (Keenan, Loeber, \& Zhang, 1995).

The function and importance of peer group plays a crucial role during adolescents (Harris, 2000; Espelage, 2010). Peer becomes very important in adolescents period because peer is a socializing agent with the world outside home. Studies found out that aggressive adolescents at school recognition, they want to become leader, powerful, socially accepted and different. It is observed by researchers that family conflict, physical punishment and harsh parenting have significant impact on children"s mind and the young adolescents who are aversive to such harsh treatment become aggressive by nature (Alink, Mesman, Zeiji, Stolk, Juffer, BakermansKraneburg, \& Ijzendroom, 2009). The role of parents, and peer group are important determinants of modelling. People who are repeatedly exposed to aggressive parent or peer models will be more assaultive in their interaction than those who are not exposed 


\section{International Journal of Science and Research (IJSR) \\ ISSN (Online): 2319-7064 \\ Index Copernicus Value (2013): 6.14 | Impact Factor (2014): 5.611}

\section{Review of Literature}

Study done by Mrug et al. (2004) found that adolescents would be more aggressive if their peers belong to aggression, antisocial activities and placed a high status. It is also found that if adolescents want to raise their status, they should behave in aggressive manner. Researchers found that peer pressure is one of the important reasons for observed aggressive behaviour in childhood and adolescence (Ryan, 2000; Santor et al, 2000; Steinberg, 1999). Keenan et al, 1995 found that peers influence each other to engage in anti social behaviour.

Eichelsheim et al. (2010) did a study on inter generational in which researchers found that negative parent child interaction leads to aggression among children. It was also found that conflicts in interaction are strongly related to aggression in both genders.

Cummings et al, (2004) conducted a study on marital conflict (family environment) with aggression among adolescents. It was revealed that conflict was associated with children's immediate aggressive responding and leads to aggression and negativity among children. Researchers also found that parents negative emotionality were associated with higher possibility in children.

Observation done by children affects their personality. Children"s observation of their parents in interpersonal contexts, particularly their parents aggression, influences the children's own social problem solving skills (Dodge, Bates, \& Pettit, 1990; Goodman, Barfoot, Frye, \& Belli, 1999; MacBrayer, Milich, \& Hundley, 2003).Effect of witnessing violence in the home on aggressive behaviour among children, found to be important predictors of crime and delinquency in later life (Hotton, 2003).

From the above review of literature we can concluded that adolescents would be more aggressive if they belongs to aggressive peers. A family conflict also leads to aggression among adolescents. Children observation and violence affects their personality negatively and they become more hostile and aggressive.

\section{Objectives}

- To study aggression in relation to peer pressure among adolescents.

- To study aggression in relation to various dimensions of family environment among adolescents.

- To study gender differences on aggression, peer pressure and on various dimensions of family environment.

\section{Hypotheses}

From the above review of literature following hypotheses have been formulated:

- It is expected that aggression relates positively with peer pressure.

- It is expected that aggression relates negatively with different dimensions of family environment.
- It is expected that there exists significant gender differences on aggression, peer pressure and on various dimensions of family environment.

\section{Methodology}

\section{Participants}

For the present investigation the sample consists of 210 adolescents (107 males, 103 females) selected randomly from different schools of Chandigarh. Students of different schools between the age 13-19 years have been taken up for the present study.

\section{MEASURES}

Manifestation of Aggression scale (R. A. Singh, 1986) is used which contains 50 items related to reactionary attitude, irritation and drive for dominance, love for fighting, anger behaviour and aggressive tendencies against social customs. It has two alternatives i.e. "right" or "wrong". Every right answer is scored 2 whereas every wrong answer is scored 1 (except for item no, 34, 42 and 45). The reliability is found to be 0.78 for the measuring aggression.

Peer Pressure (Singh \& Saini, 2010) is used which measures the pressure due to peers and it consists of 25 items. It is a uni-dimensional scale and is a self report 5point Likert scale measured Strongly disagree (5), Disagree(4), Can't say(3), Agree(2), Strongly Agree(1). There are three reverse coded items also. Positive items are scored from 1 to 5 and Negative items or reverse items are scored from 5 to 1 .

Family Relationship inventory (Sherry \& Sinha, 1987) is used measuring family relationship. It is prepared on the basis of Brunken and Crites „Family Relation Inventory ${ }^{\text {ee }}$ in the Indian situations and contains 150 items to be answered on ,true , ,false ${ }^{\text {ee }}$ alternative. Authors have reported testretest reliability values for the various scales which is found to be between 0.42 to 0.81 (Sherry \& Sinha, 1987).

\section{Procedure}

First of all proper rapport was build up with the subjects. With respect to the objectives of the present study the sample were administered on Manifestation of Aggression (R. A. Singh, 1986) which consists of 50 items, Peer Pressure (Singh \& Saini, 2010) which consists of 25 items and Family Relationship inventory by Sherry \& Sinha, (1987) which consists of 150 items. After administering, scoring was done with the help of manuals and their respective scoring keys. For data analysis descriptive statistics and t-test were calculated. 


\section{International Journal of Science and Research (IJSR) \\ ISSN (Online): 2319-7064 \\ Index Copernicus Value (2013): 6.14 | Impact Factor (2014): 5.611}

\section{Results and Discussion}

Table 1: shows the correlation matrix between aggression, peer pressure and various dimensions of family relationship among adolescents (Male-107, Female- 103)

\begin{tabular}{|c|c|c|c|c|c|}
\hline Variables & Aggression & $\begin{array}{c}\text { Peer } \\
\text { Pressure }\end{array}$ & $P A$ & $P C$ & $P V$ \\
\hline Aggression & 1 & 0.033 & 0.075 & $0.191^{* *}$ & 0.014 \\
\hline $\begin{array}{c}\text { Peer } \\
\text { Pressure }\end{array}$ & - & 1 & 0.038 & 0.018 & $0.155^{*}$ \\
\hline PA & - & - & 1 & $0.316^{* *}$ & $0.168^{*}$ \\
\hline PC & - & - & - & 1 & $0.157^{*}$ \\
\hline PV & - & - & - & - & 1 \\
\hline
\end{tabular}

$* *$ significant at 0.01 level

*significant at 0.05 level

PA - Parental Acceptance, PC- Parental Concentration, PVParental Avoidance

Table I revealed that aggression and peer pressure have a positive relationship. The calculated comes out to be 0.033 which shows there is weak but positive relationship between aggression and peer pressure. There is not significant association between these two variables. The correlation value between aggression and parental acceptance found to be 0.075 . It is also not significant. The calculated value i.e. 0.075 shows non significant association and weak association between aggression and parental acceptance. It reveals that if there is parental acceptance there is no aggression among adolescents.

Study done by Misbah \& Aisha (2011) found that there is significant weak and negative association between parental acceptance and aggression. The results depict the weak relationship between the two variables. The correlation between aggression and parental avoidance found to be 0.014 . It is also not significant because 0.014 is almost the negligible relationship. However the calculated value between aggression and parental concentration has significant association. And it is significant at 0.01 level as obtained value is greater than the table value.

The table also revealed that there is significant association between peer pressure and parental avoidance. The value comes out to be 0.155 which shows the significant relationship between two variables. It also depicts there is positive relationship between the two variables means higher the family avoidance higher will be the peer pressure.

Table II depicts the mean, S.D, p value obtained on the aggression, peer pressure and various dimensions of family relationship by males $(\mathrm{N}=107)$ and females $(\mathrm{N}=103)$

\begin{tabular}{|c|c|c|c|c|c|c|}
\hline S.No. & Variables & Gender & Mean & SD & t-ratio & P-value \\
\hline 1 & \multirow{2}{*}{ Aggression } & Male & 65.00 & 8.88 & 0.883 & $0.378 \mathrm{~ns}$ \\
\cline { 3 - 5 } & & Female & 64.04 & 6.68 & & \\
\hline 2 & \multirow{2}{*}{$\begin{array}{c}\text { Peer } \\
\text { Pressure }\end{array}$} & Male & 52.75 & 21.65 & 3.052 & $0.003^{* *}$ \\
\cline { 3 - 6 } 3 & Female & 63.57 & 29.27 & & \\
\hline 4 & PA & Male & 38.121 & 5.30 & 0.506 & $0.613 \mathrm{~ns}$ \\
\cline { 3 - 6 } & & Female & 37.69 & 6.72 & & \\
\hline 5 & PC & Male & 25.31 & 7.45 & 0.712 & $0.477 \mathrm{~ns}$ \\
\cline { 3 - 5 } & & Female & 24.62 & 6.68 & & \\
\hline \multirow{2}{*}{5} & PV & Male & 11.635 & 7.51 & 2.336 & $0.020^{*}$ \\
\cline { 3 - 5 } & & Female & 14.13 & 7.99 & & \\
\hline
\end{tabular}

**significant at 0.01 level

*significant at 0.05 level
PA - Parental avoidance, PC - Parental concentration, PV Parental avoidance

The above table revealed there are no significant gender differences between boys and girls on the variable aggression. The $\mathrm{p}$ value comes out to be 0.378 which is greater than alpha 0.05 . It shows there is no difference between two groups of adolescents. Males and females have same level of aggression. However the mean value of males i.e. 65.00 found to be slightly higher than the females i.e. 64.04 means males are higher on aggression level as compare to females. Research shows that levels or overt aggression are higher in males; however, the levels of relational aggression are equal between males and female (Bjorkqvist, Lagerspetz, \& Kaukiainen, 1992).

The $\mathrm{p}$ value of peer pressure between males and females found to be 0.003 which shows the significant gender differences. Males and females experiences differences in the peer pressure. The calculated $p$ value is less than the 0.05 alpha; it reveals the significant differences between two groups of adolescents. The mean value on peer pressure of females i.e. 63.57 is higher than the mean value of males which is found to be 52.75. It means females feel more peer pressure as compare to males. Study conducted by Helfert \& Warschburger (2013) on peer pressure during adolescence found that girls were more affected by peer pressure as compared to boys. Researchers found that girls were more frequently faced with peer teasing.

On the dimensions of family relationship there are no significant gender differences on the dimension parental acceptance and parental concentration as the calculated $\mathrm{p}$ value is greater than the 0.05 alpha i.e. 0.613 and 0.477 respectively. However the mean value of parental acceptance shows that the acceptance is higher in males as compare to females. And in the case of parental concentration the mean value is also higher in males. Parents over protect them through the more concentration and restrictions. Studies revealed that family conflicts have severe effect and long lasting effect on boys as compare to girls (Ram \& Hou, 2005).

In the third dimension of family relationship i.e. parental avoidance there is significant gender differences. The calculated $p$ value comes out to be 0.020 which is less than the 0.05 alpha. Parents avoid their children and there is differences in their avoidance they avoid female child more as compare to the male child. Parental avoidance is they are not able to satisfy the needs of the child. Parents withdraw when the child approaches them for affection and love.

\section{Conclusion and Implications}

Form the above discussion it is concluded that there is weak relationship between aggression and peer pressure and between aggression and various dimensions. There is significant association between aggression and parental concentration. Findings also showed that there are significant differences in peer pressure and family avoidance among males and females. Males are high slightly high on aggression, parental acceptance and parental concentration. The present study suggested several implications for parents 
as well as for adolescents. Parents should concern about their children. If parents avoid or neglect their child, automatically child move towards their peers for support and love and sometimes they involve into anti societal acts with peers. Family environment should be healthy so that everybody in the family enjoys the life with optimism. If family environment will not be supportive and healthy, conflicts occur between the members of the family which make their life full of negative thoughts of each other and develop aggression as well.

\section{References}

[1] Bjorkqvist, K., Lagerspetz, K., M. J. \& Kaukiainen, A. (1992). Do girls manipulate and boys fight? Developmental trends in regard to direct and indirect aggression. Aggressive Behavior, 18, 117-127.

[2] Dodge KA, Bates JE, Pettit GS. Mechanisms in the cycle of violence. Science 1990;250:1678-1683.

[3] Espelage, D. L. (2010). Bullying in early adolescence: The role of peer group.

[4] Goodman, S. H., Barfoot, B., Frye, A. A., Belli, A.M. (1999). Dimensions of marital conflict and children's social problem-solving skills. Journal of Family Psychology; 13:33-45

[5] Harris, J. R. (2000). Socialization, personality development, and the child's environment: A comment on Vendell. Developmental Psychology, 36, 711-723.

[6] Helfert, S., \& Warschburger, P. (2011). A prospective study on the impact of peer and parental pressure on body dissatisfaction in adolescent girls and boys. Body Image, 8(2), 101-109.

[7] Hotton, T. (2003). Childhood aggression and exposure to violence in the home. "Crime and Justice research paper series”. ISBN: 0-662-34418-9.

[8] MacBrayer, E. K., Milich, R., Hundley, M. (2003). Attributional biases in aggressive children and their mothers. Journal of Abnormal Psychology. 112:698708. [PubMed: 14674871].

[9] Misbah, A. \& Aisha, Z. (2011). Pakistan Journal of Psychology, Vol 42, Issue 2, Pp 1.

[10] Neumark-Sztainer D, Falkner N, Story M, Perry C, Hannan P. J, Mulert S. (2002). Weight-teasing among adolescents: Correlations with weight status and disordered eating behaviors. International Journal of Obesity. Pp. 123-131.

[11] Pung, P. W., Yaacob, S. N., Baharudin, R., \& Osman, S. (2015). Low Self-Control, Peer Delinquency and Aggression among Adolescents in Malaysia. Asian Social Science; Vol. 11, No. 21.

[12]Ram, B., \& Hou, F. (2005). Sex differences in the effects of family structure on children's aggressive behavior. Journal of Comparative Family Studies, 36 (2), 329-341.

[13] Sherry, J. P., \& Sinha, J. C. (1987). Family Relations Inventory. Agra: National Psychological Corporation.

[14].Yavuzer, Y., Karatas, Z., Civilidag, A. \&Gundogdu, R. (2014).The role of peer pressure, automatic thoughts and self-esteem on adolescents ${ }^{\text {ee }}$ aggression. Eurasian Journal of Educational Research, 54, 61-78. 